\title{
Role of Predatory Mites in Persistent Nonoccupational Allergic Rhinitis
}

\author{
Paloma Poza Guedes, ${ }^{1}$ Inmaculada Sánchez Machín, ${ }^{1}$ \\ Víctor Matheu, ${ }^{2}$ Víctor Iraola, ${ }^{3}$ and Ruperto González Pérez ${ }^{1}$ \\ ${ }^{1}$ Allergy Department, Hospital del Tórax, HUNS La Candelaria, 38320 Santa Cruz de Tenerife, Spain \\ ${ }^{2}$ Department of Clinical Sciences-Division IV, Lund University, 22100 Lund, Sweden \\ ${ }^{3}$ Laboratorios LETI, 28760 Madrid, Spain
}

Correspondence should be addressed to Ruperto González Pérez; glezruperto@gmail.com

Received 20 February 2016; Accepted 30 May 2016

Academic Editor: Christophe Leroyer

Copyright @ 2016 Paloma Poza Guedes et al. This is an open access article distributed under the Creative Commons Attribution License, which permits unrestricted use, distribution, and reproduction in any medium, provided the original work is properly cited.

\begin{abstract}
Mites can sensitize and induce atopic disease in predisposed individuals and are an important deteriorating factor in patients with allergic rhinitis, asthma, and atopic dermatitis. Although Pyroglyphidae mites have been extensively studied, very scarce reports are available on Cheyletidae spp. especially regarding human respiratory pathology. The main objective of the present study is to investigate the clinical role of this predator mite (Cheyletus eruditus) as a respiratory antigen in a selected sensitized human population. Fifty-two adult patients were recruited from the outpatient allergy clinic to assess their eligibility for the study. The thirty-seven subjects with persistent allergic rhinitis (PAR) who fulfilled the ARIA criteria had a positive IgE response confirmed by skin prick test (SPT) to C. eruditus. Only those individuals (37/47) with a positive SPT to C. eruditus showed a positive nasal provocation test (NPT), while 10 patients with nonallergic mild-to-moderate persistent rhinitis, control group, had a negative NPT with C. eruditus. The present paper describes a new role for the predator mite Cheyletus eruditus as a respiratory allergen in a selected subset of patients in a subtropical environment afflicted with persistent nonoccupational allergic rhinitis.
\end{abstract}

\section{Introduction}

The house dust mites (HDM) are described as common aeroallergens, colonizing beds, sofas, carpets, and any woven material $[1,2]$. HDM sensitize and induce atopic disease in predisposed individuals and are an important deteriorating factor in patients with allergic rhinitis, asthma, and atopic dermatitis [3-5]. Dust mites are also the main cause for respiratory allergies in the Canary Islands, a subtropical region offshore Spain. As described in some other areas of the world with similar weather characteristics pyroglyphid and nonpyroglyphid mites can be found not only in storage facilities but also in the domestic environment $[6,7]$. A report from our work group found that the predator mite Cheyletus spp. was unexpectedly frequent in house dust samples collected in our location, Tenerife [8]. Although Pyroglyphidae mites have been extensively studied, very scarce reports are available on Cheyletidae spp. especially regarding human respiratory pathology. The main objective of the present study is to investigate the clinical role of Cheyletus eruditus as a respiratory antigen in a selected sensitized human population.

\section{Material and Methods}

2.1. Subjects. We recruited adult patients consecutively with a clinically staged diagnosis of mild-to-moderate persistent allergic rhinitis according to the ARIA guidelines $[9,10]$ from the Allergy Outpatient office. Only patients with a positive skin prick test (SPT) referring to the Cheyletus eruditus extract were included in the case study group. The control group consisted of subjects presenting with mild-tomoderate persistent nonallergic rhinitis (i.e., subjects with negative SPT and/or serum specific IgE to common airborne 
allergens including Cheyletus eruditus). Pregnant and breastfeeding women were excluded. The study was approved by the Ethical Committee of the hospital and informed consent was signed by all participants.

2.2. Allergen Extract. Mite bodies of a C. eruditus culture were carefully separated from the culture medium with forceps. The mite bodies were extracted (1:10 wt/vol) in PBS $0.01 \mathrm{M}$ ( $\mathrm{pH} 7.4$ ) overnight at $4^{\circ} \mathrm{C}$ under continuous magnetic stirring. Afterwards, the extract was centrifuged, the supernatant separated, and sterile-filtered and freeze-dried. The protein content of the extract was evaluated by the LowryBiuret method (Sigma, Bedford, MA, USA), using bovine serum albumin as standard. The protein content of $C$. eruditus extract was $125.2 \mathrm{mg} / \mathrm{mL}$. The determination of specific IgE to C. eruditus was performed by LETI. The determination was done by ELISA. Briefly, $20 \mathrm{mg} / \mathrm{mL}$ of the protein extract was dissolved in carbonate/bicarbonate buffer, $\mathrm{pH}$ 9.6, and plastic microtiter plates were coated in the dissolved extract (Immulon IV; Dynex Technologies, Chantilly, VA). Each serum sample was diluted to $1: 2 \mathrm{vol} / \mathrm{vol}$ in $0.01 \mathrm{M} \mathrm{PBS}$ and incubated $(100 \mu \mathrm{L})$ for 2 hours in the wells. The plates were washed and incubated for 2 hours in anti-human IgE conjugated with peroxidase. After 5 washes, the reaction was developed for 30 minutes and then stopped with sulfuric acid $1 \mathrm{~N}$. Three individual serum samples from nonallergic patients were used as negative controls. Optical densities (ODs) 4 times the mean value of the negative controls or greater were considered positive.

2.3. Skin Prick Test and Nasal Provocation Test. Skin prick tests were performed with an extract containing $10 \mathrm{mg}$ of freeze-dried material of Cheyletus eruditus $(0.05 \mathrm{mg} / \mathrm{mL})$ and standardized extracts for the routine airborne allergens present in our area (D. pteronyssinus, D. farinae, Blomia tropicalis, cat/dog dander, Alternaria alternata, Artemisia vulgaris, Parietaria judaica, and grass pollen; Laboratorios LETI, Madrid, Spain). Histamine and saline were used as positive and negative controls. Following everyday practice, antihistamines were withdrawn a week prior to the SPT. The wheals were read after 20 minutes and those diameters greater than $3 \mathrm{~mm}$ were regarded as positive.

The measurement of the clinical response to Cheyletus eruditus was assessed by a specific nasal provocation test (NPT). A solution of Cheyletus eruditus was diluted to $0.1 \mathrm{mg} / \mathrm{mL} \mathrm{w} / \mathrm{v}$ with saline $(0.9 \%)$ to obtain dilutions at $1 / 10,1 / 100$, and $1 / 1000 \mathrm{mg} / \mathrm{mL}$ for each subject. The doses of topical (nasal and/or bronchial) steroids, antihistamines, and nasal vasoconstrictors were discontinued or minimized 2 weeks before the nasal challenge. The NPT began every morning (8:30 a.m.) to avoid possible nasal cycle influence. After a resting period of 30 minutes, both acoustic rhinometry (Rhinoscan, Interacoustics A/S, Denmark) and forced bronchial spirometry (Sibelmed, Barcelona, Spain) were performed to measure the basal nasal minimal cross-sectional area (MCA) $[11,12]$ and nasal volume $2-5.5 \mathrm{~cm}^{3}$ (Vol.) besides lung function forced expired volume in one second (FEV1). The nasal challenge was considered positive with a significant drop (above 25\%) over the basal nasal volume. Saline solution was previously sprayed into both nostrils to rule out nasal hyperresponsiveness (NHR). Increasing doses of Cheyletus eruditus were sprayed unilaterally in the same nostril while rhinometric, every $15 \mathrm{~min}$, and spirometric, every $30 \mathrm{~min}$, measures were taken after every nasal application. A clinical score was also measured throughout the nasal challenge and regarded as positive above five points $[13,14]$. The significance of changes was assessed by Mann-Whitney $U$ test. Statistical significance was assumed at $p$ values $\leq 0.05$.

\section{Results}

3.1. Patients, Sera and Skin Prick Test. Forty-seven adult patients (Table 1) were recruited from the outpatient allergy clinic to assess their eligibility for the study. The severity of the persistent allergic rhinitis (PAR) was assessed using the Allergic Rhinitis and its Impact on Asthma (ARIA) guidelines. The thirty-seven subjects (23 females and 14 males, median age 30.5 y.o.) with PAR who fulfilled the ARIA criteriaconforming to the active study group-had a positive skin prick test (SPT) to C. eruditus. Only two out of the thirty-seven subjects had a single sensitization to $C$. eruditus while the rest of the individuals were also allergic to different mitesDermatophagoides spp. and/or Blomia tropicalis. The control group consisted of 10 patients with nonallergic persistent rhinitis (i.e., subjects with a negative SPT and/or serum specific IgE to common airborne allergens including Cheyletus eruditus (control group: 6 females and 4 males median age 29.0 y.o.)).

\subsection{Specific Nasal Challenge and Acoustic Rhinometry. All} forty-seven patients included in the present study underwent a specific NPT with C. eruditus. Only those subjects (27/37) with a positive SPT to $C$. eruditus showed a positive NPT with the same specific mite while 10 patients with nonallergic mild-to-moderate persistent rhinitis-control group-had a negative NPT with $C$. eruditus. All positive nasal responses were found in the same nostril (ipsilateral) while no contralateral nasal responses alone were obtained. Nasal nonspecific reactivity was excluded by means of a saline solution sprayed into the nose prior to each specific NPT in both study groups. Mean MCA and VOL were significantly $(p<0.05)$ decreased only in those patients sensitized to $C$. eruditus. No differences were found in basal FEV1 in both groups and no changes were found in those FEV1 obtained throughout the NPT and at the end of the observation period in both groups. A positive NPT clinical score was found in the active group but not in the control subjects. One patient of the active group had a clinical score lower than 5 (3 points); a subsequent conjunctival provocation test was performed with a $C$. eruditus extract ending with a positive result at 1/10 dilution. All patients with a positive NPT were subsequently treated with a single oral antihistamine (cetirizine $5 \mathrm{mg}$ ) and topical nasal oxymetazoline. No inhaled beta-agonist, systemic steroids, or adrenaline was needed at any time and no admissions to hospital were required. Although home peak nasal inspiratory flow (PNIF) measurements were 
TABLE 1: Patient data and specific nasal provocation test with Cheyletus eruditus.

\begin{tabular}{|c|c|c|c|c|c|c|c|c|c|}
\hline $\begin{array}{l}\text { Patients } \\
(n=47)\end{array}$ & Age & $\begin{array}{c}\text { SPT } \\
\text { Cheyletus } \\
\text { eruditus }\end{array}$ & $\begin{array}{c}\text { SPT } \\
\text { Dermatophagoides } \\
\text { spp. }\end{array}$ & $\begin{array}{c}\text { SPT } \\
\text { Blomia } \\
\text { tropicalis }\end{array}$ & $\begin{array}{l}\text { NPT } \\
\text { Cheyletus } \\
\text { eruditus }\end{array}$ & $\begin{array}{c}\% \\
\text { variation } \\
\text { in MCA } \\
\text { after NPT }\end{array}$ & $\begin{array}{c}\% \\
\text { variation } \\
\text { in VOL } \\
\text { after NPT }\end{array}$ & $\begin{array}{c}\text { Cheyletus } \\
\text { eruditus } \\
\text { dilution (NPT) }\end{array}$ & $\begin{array}{l}\text { Clinical } \\
\text { score after } \\
\text { NPT }\end{array}$ \\
\hline 1 & 28 & + & + & + & + & 31.15 & 42.38 & $1: 10$ & 7 \\
\hline 2 & 38 & + & - & - & + & 34.55 & 38.51 & $1: 10$ & 6 \\
\hline 3 & 20 & + & + & - & + & 27.28 & 40.58 & $1: 100$ & 8 \\
\hline 4 & 48 & + & + & - & + & 64.29 & 72.4 & $1: 10$ & 9 \\
\hline 5 & 29 & + & + & - & + & 8.02 & 31.7 & $1: 10$ & 6 \\
\hline 6 & 21 & + & + & - & + & 51.43 & 62.56 & $1: 100$ & 6 \\
\hline 7 & 28 & + & + & + & + & 70.59 & 47.11 & $1: 100$ & 9 \\
\hline 8 & 21 & + & + & + & + & 69.24 & 86.03 & $1: 10$ & 8 \\
\hline 9 & 31 & + & + & + & + & 37.84 & 38.55 & $1: 10$ & 9 \\
\hline 10 & 23 & + & - & - & + & 41.03 & 43.69 & $1: 100$ & 7 \\
\hline 11 & 20 & + & + & - & + & 33.34 & 5.69 & $1: 1$ & 3 \\
\hline 12 & 31 & + & + & - & + & 7.41 & 43.01 & $1: 10$ & 7 \\
\hline 13 & 21 & + & + & - & + & 27.91 & 40.8 & $1: 10$ & 8 \\
\hline 14 & 24 & + & + & + & + & 50.77 & 56.91 & $1: 10$ & 6 \\
\hline 15 & 26 & + & + & + & + & 40.68 & 31.92 & $1: 10$ & 9 \\
\hline 16 & 34 & + & + & - & + & 96.97 & 94.43 & $1: 1000$ & 9 \\
\hline 17 & 45 & + & + & - & + & 33.34 & 86.66 & $1: 10$ & 8 \\
\hline 18 & 36 & + & + & + & + & 29.4 & 13.14 & $1: 100$ & 8 \\
\hline 19 & 23 & + & + & - & + & 29.04 & 32.18 & $1: 10$ & 9 \\
\hline 20 & 25 & + & + & - & + & 52.0 & 52.15 & $1: 10$ & 10 \\
\hline 21 & 34 & + & + & - & + & 25.0 & 45.57 & $1: 10$ & 7 \\
\hline 22 & 31 & + & + & + & + & 47.3 & 42.79 & $1: 100$ & 7 \\
\hline 23 & 32 & + & + & - & + & 34.15 & 18.08 & $1: 10$ & 6 \\
\hline 24 & 31 & + & + & - & + & 20.38 & 7.04 & $1: 1$ & 8 \\
\hline 25 & 30 & + & + & - & + & 27.66 & 42.48 & $1: 10$ & 9 \\
\hline 26 & 51 & + & + & + & + & 40.0 & 52.58 & $1: 10$ & 6 \\
\hline 27 & 35 & + & + & - & + & 38.58 & 22.4 & $1: 10$ & 8 \\
\hline 28 & 23 & + & + & - & + & 36.85 & 40.45 & $1: 10$ & 9 \\
\hline 29 & 24 & + & + & - & + & 48.44 & 40.31 & $1: 10$ & 6 \\
\hline 30 & 25 & + & + & - & + & 20.46 & 26.0 & $1: 100$ & 7 \\
\hline 31 & 37 & + & + & + & + & 7.41 & 37.78 & $1: 100$ & 8 \\
\hline 32 & 18 & + & + & - & + & 43.4 & 38.89 & $1: 10$ & 10 \\
\hline 33 & 18 & + & + & - & + & 18.75 & 21.81 & $1: 10$ & 9 \\
\hline 34 & 33 & + & + & + & + & 37.5 & 35.3 & $1: 1000$ & 8 \\
\hline 35 & 21 & + & + & + & + & 48.94 & 18.01 & $1: 100$ & 8 \\
\hline 36 & 31 & + & + & - & + & 17.8 & 31.27 & $1: 100$ & 6 \\
\hline 37 & 18 & + & + & + & + & 25.93 & 24.11 & $1: 10$ & 7 \\
\hline 38 & 29 & - & - & - & - & 0.71 & 4.73 & $1: 1$ & 2 \\
\hline 39 & 63 & - & - & - & - & 0.0 & 3.41 & $1: 1$ & 1 \\
\hline 40 & 22 & - & - & - & - & 0.36 & 0.0 & $1: 1$ & 1 \\
\hline 41 & 21 & - & - & - & - & 0.0 & 2.09 & $1: 1$ & 2 \\
\hline 42 & 18 & - & - & - & - & 0.30 & 0.0 & $1: 1$ & 4 \\
\hline 43 & 32 & - & - & - & - & 0.28 & 2.55 & $1: 1$ & 1 \\
\hline 44 & 27 & - & - & - & - & 0.37 & 3.23 & $1: 1$ & 2 \\
\hline 45 & 35 & - & - & - & - & 0.0 & 4.30 & $1: 1$ & 3 \\
\hline
\end{tabular}


TABLE 1: Continued.

\begin{tabular}{lccccccccc}
\hline $\begin{array}{l}\text { Patients } \\
(n=47)\end{array}$ & Age & $\begin{array}{c}\text { SPT } \\
\text { Cheyletus } \\
\text { eruditus }\end{array}$ & $\begin{array}{c}\text { Dermatophagoides } \\
\text { spp. }\end{array}$ & $\begin{array}{c}\text { SPT } \\
\text { Blomia } \\
\text { tropicalis }\end{array}$ & $\begin{array}{c}\text { NPT } \\
\text { Cheyletus } \\
\text { eruditus }\end{array}$ & $\begin{array}{c}\% \\
\text { variation } \\
\text { in MCA } \\
\text { after NPT }\end{array}$ & $\begin{array}{c}\text { variation } \\
\text { in VOL } \\
\text { after NPT }\end{array}$ & $\begin{array}{c}\text { Cheyletus } \\
\text { eruditus } \\
\text { dilution (NPT) }\end{array}$ & $\begin{array}{c}\text { Clinical } \\
\text { score after } \\
\text { NPT }\end{array}$ \\
\hline 46 & 29 & - & - & - & - & 0.29 & 0.0 & $1: 1$ & 1 \\
47 & 31 & - & - & - & - & 0.0 & 2.38 & $1: 1$ \\
\hline
\end{tabular}

SPT: skin prick test.

MCA: minimal cross-sectional area.

Vol: nasal volume in $\mathrm{cm}^{3}$ from $\mathrm{cm} \# 2$ to $\mathrm{cm} \# 5.5$ (inflammation-susceptible mucosa) in the challenged nostril.

All 37 subjects included in the active study group were treated with oral cetirizine $5 \mathrm{mg}$ and topical oxymetazoline after the positive nasal provocation test (NPT) to Cheyletus eruditus. No adrenaline or steroids were needed. The control group (10 subjects) required no medical treatment after the NPT in any case.

not assessed, no late phase reactions were reported by the patients.

\section{Discussion}

Pyroglyphidae mites, a family of house dust mites, are the most relevant antigens causing persistent respiratory allergy worldwide [3,4] and their major allergens have been extensively studied [15]. There is an ongoing progress in the understanding of the human IgE response to nonpyroglyphid storage mites and the allergenic cross-reactivity with other mite species [16-19]. Studies from several countries have shown relevant IgE-mediated allergy in rural populations and that storage mites are major allergens. Since these mites are found in homes, especially in regions with damp housing conditions, urban populations are at risk of becoming sensitized [20].

Cheyletus eruditus is a predatory mite that commonly lives in bulk food stores such as granaries. It is also often found in animal feed, bedding, house dust, poultry litter, and mammal and bird nests. In the subtropical Canary Islands, dust mites account for the most common cause for respiratory allergies. Interestingly, a high prevalence (51\%) of Cheyletus eruditus was obtained in a 2004 study of house dust samples from mattresses and carpets from this area (Tenerife, Spain) [8]. The Cheyletidae have been associated with parasitism in birds and mammals, but also in human dermatitis [21]. Yoshikawa [22] confirmed that these mites were able to bite and induce cutaneous histopathological changes in human skin. In fact, the presence of human corporal fluid was confirmed only in the stomach of Cheyletidae mites but not in other family species, like Dermatophagoides farinae, Dermatophagoides pteronyssinus, and Tyrophagus putrescentiae. The relevance of including different dust mites in the routine allergy diagnosis work-up has been previously published and several studies demonstrate the complexity of the immunologic responses to different mite species [23-25].

We initially described between 2008 and 2012 [26, 27] IgE-human sensitization and the clinical features in a selected population of 13 atopic patients sensitized to Cheyletus eruditus. Those data lead us to investigate the putative role of this "new allergen" in causing respiratory, that is, allergic rhinitis, symptoms. In the current study, a larger population of 42 cases showed IgE sensitization to Cheyletus eruditus having obtained a positive specific nasal response in all those 27 patients with persistent allergic rhinitis when exposed to this predatory mite. Despite the small size of the present sample a high degree of immunological and clinical reactivity with Dermatophagoides spp. and Blomia tropicalis was expected and confirmed by in vivo testing. As this group of patients are exposed to both pyroglyphid and nonpyroglyphid mites, further investigations are warranted to discriminate between IgE cross-reactivity and dual-sensitization. Regrettably, we only found 2 patients who were selectively allergic to Cheyletus eruditus and not to Dermatophagoides spp. or Blomia tropicalis. The current NPT with C. eruditus proved to be safe in all patients, as immediate symptoms were only locally (nasal) elicited and no late clinical reactions were recorded. Predatory mites are commonly used as biological pesticides worldwide for control of spider mites and other pests in greenhouses. In 1999, a study in bell pepper growers described the Amblyseius cucumeris as a relevant source of occupational allergy with $23 \%$ of the population having positive skin prick test reactions [28]. A subsequent work confirmed that Amblyseius cucumeris has both speciesspecific antigens and common antigens that are crossreacting with $D$. Pteronyssinus [29]. Interestingly, the predatory mites Amblyseius californicus and Amblyseius cucumeris have also been described as a cause of occupational asthma [30].

The present paper describes the potential role as a respiratory allergen for the predator mite Cheyletus eruditus in a selected subset of patients in a subtropical environment who had symptoms of persistent allergic rhinitis. As allergic respiratory patients may show different immunologic patterns of dust mite sensitization, the identification of new allergens is critical to achieve an accurate diagnosis and relevant treatment of their allergic conditions. Our findings suggest that the predatory mite Cheyletus spp. may be considered a relevant airborne allergen not only in occupational respiratory medicine but also in persistent nonoccupational allergic rhinitis especially in those populations living in humid tropical and/or subtropical climates.

\section{Competing Interests}

All authors declare that they currently do not have any competing interests. 


\section{Acknowledgments}

This study was supported by Fundación de la Sociedad Española de Alergia e Inmunología Clínica (SEAIC).

\section{References}

[1] E. Fernandez-Caldas, R. W. Fox, G. A. Bucholtz, W. L. Trudeau, D. K. Ledford, and R. F. Lockey, "House dust mite allergy in Florida. Mite survey in households of mite-sensitive individuals in Tampa, Florida," Allergy Proceedings, vol. 11, no. 6, pp. 263267, 1990.

[2] T. Baqueiro, F. M. Carvalho, C. F. Rios et al., "Dust mite species and allergen concentrations in beds of individuals belonging to different urban socioeconomic groups in Brazil," Journal of Asthma, vol. 43, no. 2, pp. 101-105, 2006.

[3] M. A. Calderón, A. Linneberg, J. Kleine-Tebbe et al., "Respiratory allergy caused by house dust mites: what do we really know?" Journal of Allergy and Clinical Immunology, vol. 136, no. 1, pp. 38-48, 2015.

[4] M. Sánchez-Borges, A. Capriles-Hulett, and S. Malka, "Inhalant allergens clinically signification in Latin America," Allergy and Clinical Immunology International, vol. 16, no. 1, pp. 28-32, 2004.

[5] A. J. Sybilski, M. Zalewska, K. Furmańczyk, A. Lipiec, E. Krzych-Fałta, and B. Samoliński, "The prevalence of sensitization to inhalant allergens in children with atopic dermatitis," Allergy and Asthma Proceedings, vol. 36, no. 5, pp. e81-e85, 2015.

[6] E. R. Tovey, M. D. Chapman, C. W. Wells, and T. A. E. PlattsMills, "The distribution of dust mite allergen in the houses of patients with asthma," American Review of Respiratory Disease, vol. 124, no. 5, pp. 630-635, 1981.

[7] A. Custovic, A. Simpson, and A. Woodcock, "Importance of indoor allergens in the induction of allergy and elicitation of allergic disease," Allergy, vol. 53, no. 48, pp. 115-120, 1998.

[8] V. Iraola Calvo and E. Fernández-Caldas, Mapa Acarológico de España, Laboratorios LETI, Barcelona, Spain, 2009.

[9] J. Bousquet, N. Khaltaev, A. A. Cruz et al., "Allergic rhinitis and its impact on asthma (ARIA) 2008 update (in collaboration with the World Health Organization, GA2LEN and AllerGen)," Allergy, vol. 63, Supplement s86, pp. 8-160, 2008.

[10] J. L. Brożek, J. Bousquet, C. E. Baena-Cagnani et al., "Allergic Rhinitis and its Impact on Asthma (ARIA) guidelines: 2010 revision," Journal of Allergy and Clinical Immunology, vol. 126, no. 3, pp. 466-476, 2010.

[11] D. Y. Wang, M. T. Raza, D. Y. T. Goh, B. W. Lee, and Y. H. Chan, "Acoustic rhinometry in nasal allergen challenge study: which dimensional measures are meaningful?" Clinical and Experimental Allergy, vol. 34, no. 7, pp. 1093-1098, 2004.

[12] S. P. Straszek, V. Schlünssen, T. Sigsgaard, and O. F. Pedersen, "Reference values for acoustic rhinometry in decongested school children and adults: the most sensitive measurement for change in nasal patency," Rhinology, vol. 45, no. 1, pp. 36-39, 2007.

[13] E. W. Fisher, V. J. Lund, and G. K. Scadding, "Acoustic rhinometry in rhinological practice: discussion paper," Journal of the Royal Society of Medicine, vol. 87, no. 7, pp. 411-413, 1994.

[14] R. González Pérez, R. Vives Conesa, and A. Hardisson de la Torre, Test de provocación nasal con acetil-salicilato de lisina [Ph.D. thesis], Servicio de Publicaciones, Universidad de La Laguna, San Cristóbal de La Laguna, Spain, 2005.
[15] J. C. Bessot and G. Pauli, "Mite allergens: an overview," European Annals of Allergy and Clinical Immunology, vol. 43, no. 5, pp. 141-156, 2011.

[16] V. Iraola, M. Prados, H. Pinto, M. Morales, J. R. Leonor, and J. Carnés, "Allergological characterisation of the storage mite Acarus gracilis (Acari: Acaridae)," Allergologia et Immunopathologia, vol. 43, no. 4, pp. 332-338, 2015.

[17] M. Morales, V. Iraola, J. R. Leonor, and J. Carnés, "Enzymatic activity of allergenic house dust and storage mite extracts," Journal of Medical Entomology, vol. 50, no. 1, pp. 147-154, 2013.

[18] C. Jiang, X. Fan, M. Li et al., "Characterization of Der f 29, a new allergen from dermatophagoides farinae," American Journal of Translational Research, vol. 7, no. 7, pp. 1303-1313, 2015.

[19] E. C. Liao, C. M. Ho, M. Y. Lin, and J. J. Tsai, "Dermatophagoides pteronyssinus and Tyrophagus putrescentiae allergy in allergic rhinitis caused by cross-reactivity not dual-sensitization," Journal of Clinical Immunology, vol. 30, no. 6, pp. 830-839, 2010.

[20] M. van Hage-Hamsten and E. Johansson, "Clinical and immunologic aspects of storage mite allergy," Allergy, vol. 53, no. 48 , pp. 49-53, 1998.

[21] O. Ezequiel, G. S. Gazêta, and N. M. Freire, "Dermatological manifestations caused by mites of the Cheyletidae family: a case report," Anais Brasileiros de Dermatologia, vol. 78, no. 1, pp. 8790, 2003.

[22] M. Yoshikawa, "Feeding of Cheyletus malaccensis (Acari: Cheyletidae) on human body fluids," Journal of Medical Entomology, vol. 24, no. 1, pp. 46-53, 1987.

[23] C. M. Luczynska, P. Griffin, R. J. Davies, and M. D. Topping, "Prevalence of specific IgE to storage mites (A. siro, L. destructor and T. longior) in an urban population and crossreactivity with the house dust mite (D. pteronyssinus)," Clinical and Experimental Allergy, vol. 20, no. 4, pp. 403-406, 1990.

[24] C. Zhang, J. Li, X. Lai et al., "House dust mite and storage mite IgE reactivity in allergic patients from Guangzhou, China," Asian Pacific Journal of Allergy and Immunology, vol. 30, no. 4, pp. 294-300, 2012.

[25] H. T. Lâm, L. Ekerljung, A. Bjerg, N. Văn Tường, B. Lundbäck, and E. Rönmark, "Sensitization to airborne allergens among adults and its impact on allergic symptoms: a population survey in northern Vietnam," Clinical and Translational Allergy, vol. 4, article 6, 2014.

[26] R. González-Pérez, P. Poza-Guedes, V. Matheu et al., "Preliminary data of selected population sensitized to cheyletus eruditus," Journal of Allergy and Clinical Immunology, vol. 121, no. 2, p. S91, 2008.

[27] R. Gonzalez-Perez, P. Poza-Guedes, V. Matheu, V. Iraola, J. Iglesias-Souto, and I. Sanchez-Machin, "Specific nasal provocation test with predator mites," Journal of Allergy and Clinical Immunology, vol. 129, no. 2, Article ID AB111, 2012.

[28] G. C. Groenewoud, C. de Graaf in 't Veld, A. J. vVan Oorschotvan Nes et al., "Prevalence of sensitization to the predatory mite Amblyseius cucumeris as a new occupational allergen in horticulture," Allergy, vol. 57, no. 7, pp. 614-619, 2002.

[29] N. W. de Jong, G. C. M. Groenewoud, R. van Ree et al., "Immunoblot and radioallergosorbent test inhibition studies of allergenic cross-reactivity of the predatory mite Amblyseius cucumeris with the house dust mite Dermatophagoides pteronyssinus," Annals of Allergy, Asthma and Immunology, vol. 93, no. 3, pp. 281-287, 2004.

[30] S. G. Skousgaard, T. Thisling, C. Bindslev-Jensen, and J. Baelum, "Occupational asthma caused by the predatory beneficial mites Amblyseius californicus and Amblyseius cucumeris," Occupational and Environmental Medicine, vol. 67, no. 4, p. 287, 2010. 


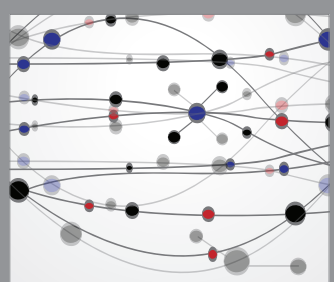

The Scientific World Journal
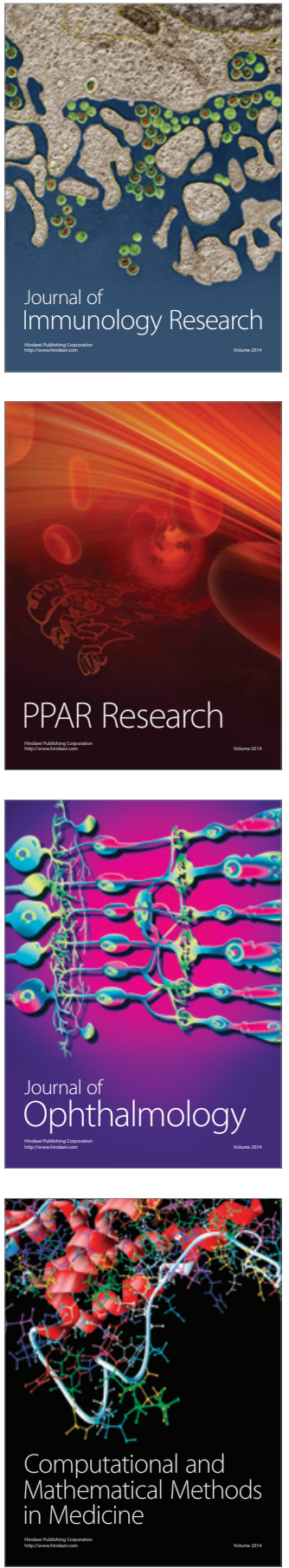

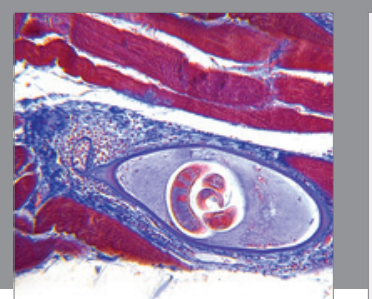

Gastroenterology Research and Practice

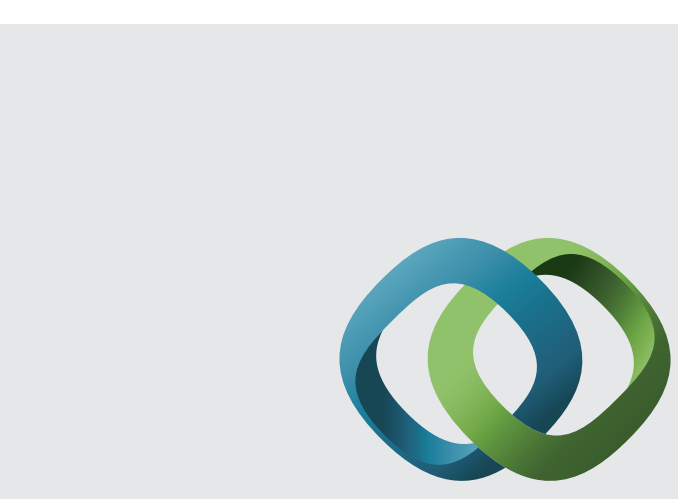

\section{Hindawi}

Submit your manuscripts at

http://www.hindawi.com
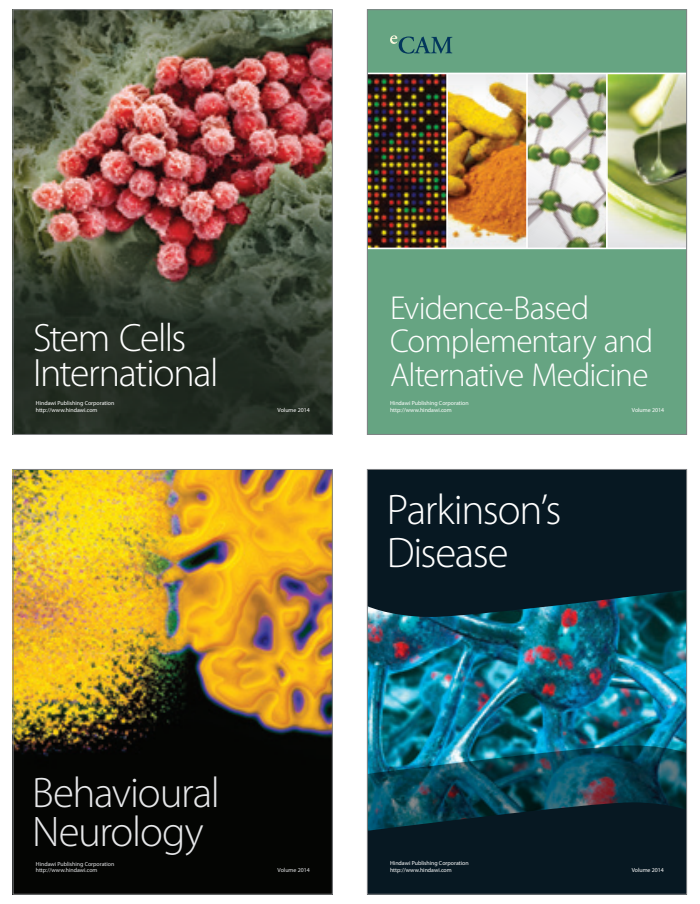
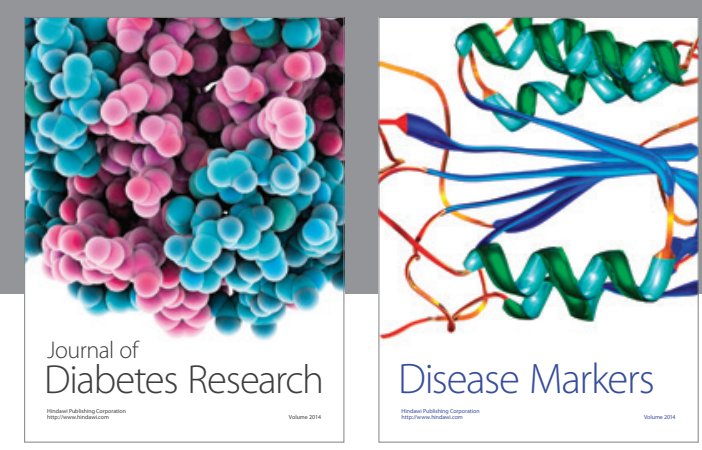

Disease Markers
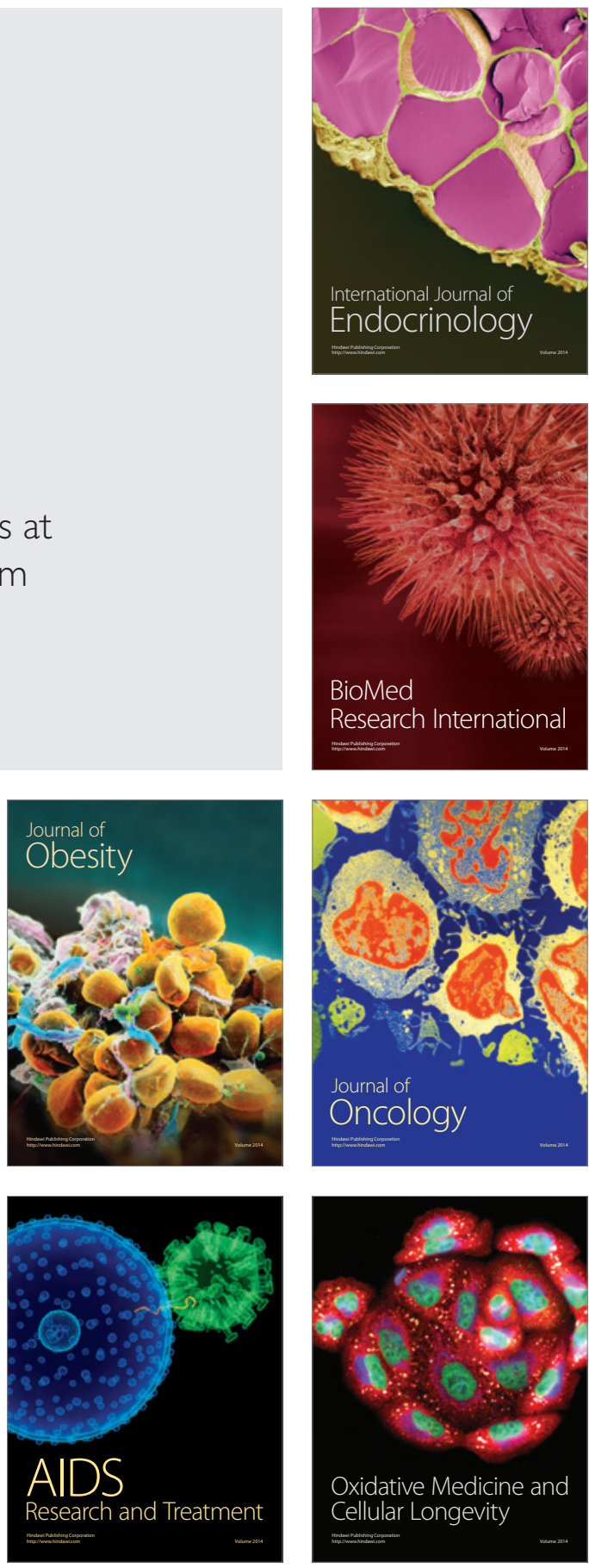